\title{
LA ESCRITURA A LA INTEMPERIE DEL LENGUAJE EN ENRIQUE LIHN Y GERMÁN MARÍN
}

\author{
The writing in the outside of the language in Enrique Lihn and Germán Marin
}

\author{
Mariela Fuentes Leal * \\ Juan Zapata Gacitúa **
}

\begin{abstract}
RESUMEN
En este artículo, planteamos que las obras El arte de la palabra de Enrique Lihn e Historia de una absolución familiar de German Marín aparecen como expresiones del silencio, según la noción de "escritura del desastre" de Maurice Blanchot, y manifestación de "El pensamiento del afuera", de acuerdo a la reflexión de Michel Foucault; esto, en el contexto de los acontecimientos políticos ocurridos en Chile a partir del año 1973. Los proyectos narrativos de ambos escritores chilenos describen la cultura oficial, mediatizada por un lenguaje vinculado al poder y, a la vez, presentan la palabra poética del desastre, a través de un lenguaje a la intemperie de la representatividad y que materializa una visión de la realidad censurada.
\end{abstract}

Palabras clave: Enrique Lihn, Germán Marín, escritura del desastre, pensamiento del afuera, exilio.

\footnotetext{
* Facultad de Humanidades y Arte, Universidad de Concepción. Concepción, Chile. Correo electrónico: mariefue@udec.cl

** Este artículo es uno de los últimos trabajos realizados junto al Dr. Juan Zapata Gacitúa, quien falleció en abril de 2015 .
}

Artículo recibido el 03 de febrero de 2015. Aceptado el 04 de septiembre de 2015. 


\begin{abstract}
In this article, we propose that the Works El arte de la palabra by Enrique Lihn and Historia de una absolución familiar by Germán Marín appear as expressions of silence, following Maurice Blanchot's idea "the writing of the disaster", and as a manifestation of "thought from the outside", according to Michel Foucault. All of the above in the context of political events that took place in Chile since 1973. The narrative projects of both Chilean writers describe the oficial culture influenced by a language related to power and simultaneosusly they reveal that the poetic word of the disaster through a language outside of representation that materializes a vision of the censored reality.
\end{abstract}

Keywords: Enrique Lihn, Germán Marín, the writing of the disaster, the thought from the outside, exile.

\title{
INTRODUCCIÓN
}

En este trabajo, comprobamos la estrecha relación de amistad y en la escritura entre Enrique Lihn y Germán Marín ${ }^{1}$. En efecto, la fascinación por una "literatura de contrabando"2, vinculada a la experimentación, y una atracción por la marginalidad aproximó a los escritores Enrique Lihn y Germán Marín desde la década de los sesenta hasta la muerte del primero de ellos ${ }^{3}$. Ambos mantuvieron

\footnotetext{
${ }^{1}$ Este artículo se inscribe en el Proyecto de Investigación "Enrique Lihn en el siglo XXI: Desplazamientos teóricos, críticos y analíticos, Proyecto DIUC N²10.062.045-1.0. Dirección de Investigación de la Universidad de Concepción. Investigador responsable: Dr. Juan Zapata Gacitúa. Co-investigadora: Dra. Mariela Fuentes Leal.

${ }^{2}$ Es un término mencionado por Enrique Lihn para referirse a una literatura que no reconoce las propiedades territoriales de los géneros, en la entrevista a Patricia Moscoso "Enrique Lihn, un escritor a la intemperie", Cosas No 81, Santiago de Chile, (8 de noviembre de 1979): 32-33.

${ }^{3}$ En conjunto, crearon la revista mensual Cormorán, dedicada al arte, la literatura y las ciencias sociales, publicada en siete números, entre los ańos 1969 y 1971; articulada desde una perspectiva crítica de izquierda sobre los acontecimientos culturales en aquella época. En esta misma publicación, Enrique Lihn y Germán Marín inventan la figura de un columnista ficticio llamado Gerardo de Pompier, a cargo de Enrique Lihn, quien se convertirá en su alter ego y aparecerá en una serie de publicaciones posteriores. Tales como La orquesta de cristal (1976), Lihn \& Pompier (1978) y El arte de la palabra (1980) y, también, en algunos poemas. Por su parte, Germán Marín ha continuado el estudio de la obra de Enrique Lihn. En 1997, editó El circo en llamas, que reúne los escritos crítico-teóricos de Enrique Lihn a nueve años de su muerte. Diez años después, publicó el cuento "Lihneas discontinuas" en su libro Basuras de Shanghai (2007), cuyo protagonista es Enrique Lihn. Así también, en la trilogía Historia de una absolución familiar, en el tercer volumen, La ola muerta (2005), Marín se refiere a la correspondencia mantenida con Enrique Lihn e incluso menciona su muerte (2005: 292-293). Además, la figura de Lihn es ficcionalizada como un personaje de la trilogía, pues reaparece para invitar a bailar a Betty Catileo en el Ferryboat American Boy, que transporta tanto personajes reales como ficticios insertos en los tres tomos de la trilogía, navegando por el río Imperial.
} 
una estrecha relación de amistad y diálogo respecto a una literatura transgresora frente a los poderes fácticos y a la tradición literaria y, a la vez, propusieron una literatura imaginativa e intransitiva expresada en una desarticulación de la escritura conclusa y a la intemperie del lenguaje. Vale decir, los autores crearon una realidad solo posible dentro de lo imposible, en un espacio literario inacabado e imperfecto.

De esta manera, analizaremos la novela El arte de la palabra (1980) de Enrique Lihn y la trilogía Historia de una absolución familiar, compuesta por las novelas Círculo vicioso (1994), Las cien águilas (1997) y La ola muerta $(2005)^{4} \mathrm{de}$ Germán Marín. Lo anterior desde la reflexión de Maurice Blanchot y su concepto "la escritura del desastre", desarrollado en sus libros El espacio literario (1992) y La escritura del desastre (1990); además, desde la noción de "el pensamiento del afuera", presente en El pensamiento del afuera (1997) y De lenguaje y literatura (1994) de Michel Foucault; asimismo, tenemos en cuenta la reflexión de Gilles Deleuze en La literatura y la vida (1994). El propósito es examinar cómo la escritura lihneana y mariniana proponen la invención de una literatura transgresora y original situada fuera de los órdenes discursivos sometidos a los poderes del mercado o a la propia realidad.

En primer lugar, los textos de Blanchot destacan el carácter nómade e interrogativo de la literatura cuya experiencia reflexiva se asemeja a una espiral de paradojas, que arrastra al escritor hacia la ausencia del tiempo histórico. Así, la escritura se constituye en un diálogo inconcluso que borra, todo presente y presencia, e incluso la voz del autor; donde 'el yo se convierte en él' en la neutralidad de la escritura y su fascinación afirmada en la soledad del espacio neutro del afuera, en la indeterminación y la errancia del infinito.

En segundo lugar, "el pensamiento del afuera", desarrollado por Michel Foucault, en su libro homónimo (1997), dedicado a Maurice Blanchot, trabaja la noción de escritura vinculada al acto de pensar en distancia, ya que el nombre define un objeto como diferente a sí mismo y, por ende, la escritura surge de esa distancia y habla desde la diferencia en el nombre dado. De este modo, Foucault concibe la palabra como "la inexistencia manifiesta de aquello que designa; ahora se sabe que el ser del lenguaje es la visible desaparición de aquel que habla" (1997:37). En ese espacio intersticial, el pensamiento del afuera permite hablar al lenguaje por sí mismo, desautorizando al sujeto pensante y creando la experiencia del afuera, mediante una escritura transgresora, que cuestiona y niega la relación significante y significado; donde escribir es pensar sin normas y escapar a la racionalidad del discurso. En otras palabras, es el pensamiento de lo imposible y de lo impensado, que no necesita una presencia de representación para otorgar

${ }^{4}$ Coincidentemente, Marín comenzó a escribir esta trilogía en 1980, el año de la publicación de $E l$ arte de la palabra de Enrique Lihn. 
sentido, en tanto habla por medio del silencio. También, Foucault plantea la idea de la intransitividad radical de la literatura en su libro De lenguaje y literatura. Aquí propone la idea de la palabra esparcida recurvada sobre sí misma y convertida en silencio; estableciéndose, de esta forma, una conexión con Blanchot.

En tercer lugar, Gilles Deleuze, en su texto La literatura y la vida, define la escritura inseparable del devenir en una zona de vecindad, donde la literatura surge cuando nace en el sujeto una tercera persona que le desliga del poder del decir yo (1994: 24); así, la escritura es descrita por el filósofo como devenir inacabado "siempre en curso, y que desborda cualquier materia vivible o vivida. Es un proceso, es decir un paso de Vida que atraviesa lo vivible y lo vivido" (1994: 13).

En relación con lo anterior, la escritura lihneana y mariniana configuran una literatura creadora de una nueva realidad. Mediante la experimentación del propio lenguaje, las palabras son liberadas de su orden discursivo y, por tanto, evitan ser degradadas y mediatizadas por figuras de poder y la tradición. Específicamente, la experiencia de la neutralidad de la escritura y el pensamiento del afuera surgen desde un exilio interior, en Lihn y Marín, causado por la dictadura militar en Chile, iniciada en 1973. Ambos hablan desde el silencio del exilio interior ${ }^{5}$ y presentan una literatura de contrabando fuera de las categorías de los géneros literarios, a distancia de una realidad ordenada, con un lenguaje rizomático, que quebranta las áreas de significación y se abre a un mundo ficticio, donde el silencio de la escritura aparecerá en forma de "cháchara" (Lihn) o "zozobra" (Marín).

Por una parte, Lihn permanece en el país después del 11 de septiembre y traza su obra usando máscaras histriónicas para insinuar la realidad y la enfrenta mediante la comicidad, la cháchara, y la parodia de sus personajes. De este modo, Lihn evita la censura, y, a la vez, crea una nueva realidad solo posible en el espacio del afuera. Desde la perspectiva de Foucault sería "la palabra literaria (que) se desarrolla a sí misma, formando una red en la que cada punto, distinto de los demás, a distancia incluso de los más próximos, se sitúa por relación a todos los otros en un espacio que los contiene y los separa al mismo tiempo" (1997: 5). En efecto, la palabra de la obra de Lihn se pronuncia desde el afuera para hacerse visible y "denunciar la susodicha perversión como una enfermedad moderna o de la modernidad literaturesca, pero se arriesgaba a hacerlo cuando ya la poesía y hasta la misma "prosa artística" para no ser menos, hacían de la oscuridad su ley y del proyecto de definir lo indefinible uno de los fundamentos de su originalidad" (1980: 211). Por otra parte, Germán Marín habla, exiliado en España durante la

\footnotetext{
${ }^{5}$ Por supuesto, utilizamos esta expresión más allá de su sentido más básico; es decir, de exilio político al interior del país; tal como se usó para referirse a la situación de los escritores disidentes al régimen militar y que permanecieron en Chile después de los acontecimientos del 11 de septiembre de 1973.
} 
elaboración de su obra, con acidez deliberada y transparencia, conservando su nombre en la escritura, en su diario de vida por veinticinco ańos. Con frecuencia, este texto expresa su angustia y soledad provocada por la experiencia pasada y se hace cargo de los aportes culturales de las artes en dos épocas, la contada en el relato familiar y la presente en el exilio, donde no hay respeto por nada ni nadie.

Por lo anterior, ambos escritores evitan violentar la realidad y solo la indican en el lenguaje. Lihn a través de una ciudad imaginaria y el discurso alborozado de Pompier y Marín por medio de la privación social y su desazón escritural. En este sentido, Foucault señala con respecto al afuera "las palabras dejan de entrecruzarse con las representaciones sólo existe en una determinada dispersión un desparramamiento, una multiplicidad misteriosa. La pregunta de Nietzsche ¿quién habla?, se encuentra con la respuesta de Mallarmé "la palabra misma, su ser enigmático y precario" (1994: 16-17).

\section{DOS OBRAS EN EL AFUERA DE LA CRÍTICA LITERARIA}

Lamentablemente, las obras El arte de la palabra e Historia de una absolución familiar han estado, prácticamente, fuera de la crítica literaria, exceptuando la crítica periodística en el momento de su publicación y algunos estudios sistemáticos. Por esto, haremos una revisión crítica relativa a las obras como un primer acercamiento a su compleja comprensión desde el punto de vista de la interrogación de los límites del lenguaje en el contexto de la dictadura de Augusto Pinochet.

Particularmente, Enrique Lihn ambienta su obra El arte de la palabra en la República Independiente de Miranda en el espacio imaginario descrito por él mismo como "un lugar oral, lenguaraz tal como es Hispanomérica, donde la realidad la parchamos, encubrimos, mentimos y desfiguramos sobre la base de la palabra. El arte de la palabra sería el arte de reemplazar la realidad por el lenguaje" (Marras, 1981: 8). "Una expresión ironizada de la poética" que funciona para Lihn como un "encuentro entre dos formas de oralidad: la que tiene poder y la que no lo tiene" con la finalidad de "demostrar cómo en ciertas operaciones del lenguaje, se miente, se calla, se manipula. Esta es la palabra autorizada que no dice nada, o la que dice una cosa por otra y la palabra degradada, al servicio del poder" (Foxley,1980: 49). Por esto, el escritor cuestiona el lenguaje constantemente, a través de diversos mecanismos, tales como: el humor negro, lo grotesco, la sátira, la parodia, entre otros, por medio de los cuales presenta una obra llena "de subtextos, de sobreentendidos, de flechas semánticas, de especulaciones filosóficas (donde) el lenguaje adquiere de esta manera un espesor antinatural" (Filebo, 1980: 7). Por su parte, Rodrigo Cánovas, en su libro Lihn, Zurita, Ictus, Radrigán: Literatura chilena y experiencia autoritaria (1986), realiza una lectura sintomal del texto El arte de 
la palabra ${ }^{6}$, que interroga las reglas y prohibiciones de la cultura, mediante un pensamiento satírico y crítico, de los órdenes culturales construidos por el hombre en su texto y que "habla a espaldas de una tradición cultural que vincula el quehacer literario en torno a un proyecto trascendente. En Lihn, la literatura es un espacio donde se parodian los distintos lenguajes que constituyen nuestra subjetividad. La literatura no es un lugar donde se defiende una identidad cultural [...] sino donde se pone en tela de juicio cualquier orden implantado por el ser humano" (1986:15). Particularmente, Cánovas destaca diversas estrategias empleadas en la novela como el uso de caricaturas en vez de personajes para hablar sobre lo prohibido y elaborar una sátira a la literatura institucionalizada y a los discursos oficiales.

Por otro lado, Leonidas Roberto Hozven, en la revista Estudios filológicos 17 (1982), plantea El arte de la palabra como el espacio de interlocución espuria entre tres protagonistas, dos expresos y un tercero ausente en busca de lo que no llega a escribirse. El primero ocurre cuando el lector cree tener cierta supremacía sobre el texto en tanto observa algunos idiomatismos o tópicos que ha dejado en el camino el narrador. El segundo sucede cuando el lector averigua que los signos anteriores han sido planificados y previstos por el narrador. Aun más, Hozven plantea la utopía del texto en tanto trata de escapar de la repetición y escenificar la coexistencia de una serie de niveles del habla en el español (político, intelectual, periodístico), ya que, en general, la escenificación de todos aquellos discursos "sin costo de escritura desde el momento que al escribir o hablar se lo hace siempre el favor de la corriente, al dictado de la corriente"(1982: 99). En cambio, Lihn escribe una parodia para desautorizar a las autoridades y desestructurar los discursos como mecanismos transitivos que presuponen un vínculo entre los organizadores de una sociedad hecha de reglas y el lenguaje como una de sus expresiones saturadas en la cháchara de sus personajes. En su obra, la escritura se vuelve disparatada, quebranta la sociedad de la República de Miranda como escenario racional y la convierte un juego donde la experiencia de la escritura está proyectada en lo imaginario. Por consiguiente, el autor crea una literatura, fuera de las convenciones sociales, descontaminada del discurso del poder y obtiene una literatura a la intemperie. En palabras del propio Lihn, definida como una "antiutopía; un lugar en que no se puede vivir, un lugar abominable. Me propuse utilizar el espacio del lenguaje que es el lenguaje donde existen ciertas cosas que no existen en otra parte para crear la situación de un espacio invivible" (Marras, 1981: 7). Para esto, la escritura de Lihn funciona en base a la poética de los procedimientos la cual le permite construir un discurso literario abierto a distintas expresiones en una misma obra.

\footnotetext{
${ }^{6}$ La lectura sintomal es una propuesta psicoanalítica de Freud, trabajada por Lacan y Lévi-Strauss, entre otros. Considera que un texto (la vida, la cultura, el lenguaje) tiene dos registros: Uno consciente y uno inconsciente, cada uno gobernado por una lógica singular, en un modelo teórico anti-mimético de conocimiento (Cánovas, 1986: 10-15).
} 
Por otra parte, la trilogía de Germán Marín también problematiza la novela como género y el sentido de la obra cuando incorpora una mixtura de géneros literarios: libro/novela de memorias, ensayo, crónica, diario, testimonio, etc., que permite configurar una cartografía experimental de su literatura; estableciendo, según Rodrigo Pinto a propósito de La ola muerta, "múltiples juegos y diversos niveles de escritura y de lectura" (2006: 7). De hecho, Marín rechaza la división de géneros literarios, en tanto "siento que ficción y ensayo están llenos de vasos comunicantes. Lo imaginario también es real. Por eso, todos estos recursos formales son juegos de espejos que me permiten la introspección" (Rivera, 1997: 32). Conjuntamente, por una parte, el autor reflexiona sobre el proceso de gestación de la escritura en una constante búsqueda sobre sí misma, donde, algunas veces, el lenguaje se escabulle en el espacio del afuera y en otras se quebraja, intempestivamente, en largas oraciones. En este sentido, Camilo Marks (2010) señala que la trilogía Hdaf " "tanto en el fondo como en la forma, es una interrogación acerca de su propia estructura y contenido, un cuestionamiento sobre lo que se pone en el papel [...], en síntesis, una inquisición sobre cómo se escribe, cómo se logra escribir una novela" (224). Por otra parte, esta posibilidad se vincula con la búsqueda de un pasado familiar, cultural y social a través del ejercicio de narrar. Igualmente, el crítico Carlos Ossa percibe una escritura deliberada en la novela Círculo vicioso y la define como un juego lúdico incitado por una abundancia de citas (1995: 22). Por otro lado, la académica Alejandra Oyarce destaca la escritura de Círculo vicioso como expresión de una cultura chilena fractal, en tanto "escritura fractal, objeto fractal, marginal, hecha de fallas, provisional, fragmentaria, que no es otra cosa que la expresión de una cultura fractal, marginal, fragmentaria: la cultura chilena, que brota de un país que para Marín se define conflictivamente, como en crisis aguda" (Oyarce Orrego, 2000: 69-70).

Ahora bien, el propio Marín ha señalado escribir desde la negatividad y la derrota, en tanto "había que retroceder, porque lo que había pasado en Chile, estaba deshaciendo todos los proyectos utópicos, ilusiones y prejuicios que nosotros teníamos respecto a la historia del país. Tenía que revisar el pasado" (Coloma, 2003: 53-61). De este modo, la escritura de Marín es un acto de vivencia y sobrevivencia en el exilio lo cual le da la posibilidad de reunir el pasado y el presente para crear una realidad imaginativa e intransitiva. Particularmente, la escritura mariniana es una representación enigmática y escurridiza en las manos de su autor, en tanto se niega a ser definida ni delimitada en el espacio literario, donde el propio Marín reconoce hacer "un intento de radiar, de crear círculos concéntricos de esta visión vuelta hacia atrás, de rodearla, de mortificarla, de cruzarla, de someterla, de aprisionarla, lo que es difícil" (Osorio, 1997: 44). Por consiguiente, la trilogía presenta textos

${ }^{7}$ Desde este momento, emplearemos la abreviatura Hdaf para referirnos a la trilogía Historia de una absolución familiar. 
inacabados, obras en construcción, donde la ficción adquiere las características de un borrador "donde mucho de lo que se dice resulta incierto, mudable, vacilante, experimental" (Marks, 2005: 3). Ciertamente, este último comentario de Camilo Marks hacia Círculo vicioso puede extrapolarse a los otros dos tomos de la trilogía Hdaf, en tanto los tres textos están estructurados de la misma forma y continúan con la misma temática. Lo mismo sucede respecto al comentario de Patricia Espinosa sobre Las cien águilas cuando la describe como "un tipo de literatura sobrecodificada y sobre "decodificada", ya que casi se lee ella misma" (1997: 34) a través de múltiples voces expresada por "citas bibliográficas, cinematográficas, musicales, semánticas o literarias, a la par que registra todo tipo de elementos propios de la cultura del pastiche y, finalmente, el discurso que entremezcla el dolor del exilio, la nostalgia por el pasado y la conciencia del acto de escritura" (1997: 34).

En síntesis, la revisión crítica de los textos estudiados permite constatar a El arte de la palabra y a Hdaf como obras de un lenguaje a la intemperie cuyos autores son despojados de todo poder, a través de la escritura del desastre, que no se deja apresar por ninguna identidad, separándose todo sentido y unidad que pueda imponérsele. Por un lado, Lihn rechaza las palabras viciadas utilizadas por las figuras e instituciones del poder y las muestra a través de la representación de una sociedad grotesca hecha de reglas; entre ellas, el lenguaje, cuya alteración provoca un quebrantamiento desquiciante en la sociedad y en su propia escritura. Por otro lado, Marín trata de constatar la escritura de forma inmediata, a través de su diario de vida, donde escribir es borrarse del presente y expresar la angustia proveniente de la inaceptabilidad de su experiencia cotidiana, a la que fue arrojado involuntariamente, para caer en la ausencia incesante de su desapropiación como sujeto.

\section{LA FASCINACIÓN POR EL ERRANTE PENSAMIENTO DEL AFUERA}

La invención de Gerardo de Pompier y Venzano Torres como alter ego de los escritores Enrique Lihn y Germán Marín, respectivamente, presupone un juego literario transgresor y experimental. Mediante estas figuras y sus narradores, los autores teorizan su propia literatura y critican el lenguaje en los niveles discursivos para articular una escritura incesante e inacabada, que pervierte la lógica racional en la indeterminación de un sentido.

Por una parte, Lihn señala "lo real en la literatura es el lenguaje, siendo su referente el modo mismo de fabricación: el modo de pegar, torcer o alinear las palabras [...] El lenguaje es tan real como cualquier otra cosa; es una especie de segundo cuerpo. Un instrumento para proponer o denegar proyectos. De manera 
que decir lenguaje es pensar en todas las implicaciones que éste tiene" (Moscoso, 1979: 32). De este modo, la escritura de Lihn está suscrita en 'el afuera', donde la palabra literaria se desarrolla a sí misma en un espacio neutro, sin límites ni tiempos. El lugar en el cual, según Foucault "el ser del lenguaje no aparece por sí mismo más que en la desaparición del sujeto"(1997: 6), situándose en el vacío. El propio Gerardo de Pompier declara sobre sus obras "la mayoría de ellas, no las escribo yo. Lo vería usted si se tomara el trabajo de leerlas; allí soy, en general, el llamado ausente de las gramáticas árabes -la tercera persona- aunque el redactor ocasional de esos escritos desaparezca aplastado por esa ausencia" (172).

Por otra parte, Germán Marín construye una creación literaria que escapa a los géneros literarios tradicionales y provoca un estado de tensión hacia el afuera de la literatura. Así, experimenta diversas formas creativas, las cuales relaciona con otras disciplinas, como la filosofía, la lingüística y la historia. Según lo dicho, la obra mariniana se despliega como una confidencia personal que escapa a los propósitos de Marín, quien adquiere la categoría de un vector que está ahí provisoriamente, porque está en constante transformación, en un proceso sin fin. Aquí, el pensamiento y la vida se unen para devenir una escritura intensa, creativa y nómade que lo ayuda a sobrevivir en la cotidianidad.

En efecto, el autor reconoce, a veces, estar ausente en la escritura "yo soy otro cuando escribo y ese doble expresa lo que no digo" (Marín, 1997: 358) y crea la figura de Venzano Torres, con quien establece un encuentro epistolar de exiliados, frente a la necesidad de tener un oyente cuando es "emboscado en una primera persona ausente, lectora y crítica de sí misma con la necesidad de tener un interlocutor" (Marín, 1997: 17). De esta manera, el escritor ficcionaliza la memoria a modo de un juego de dobles y máscaras "Conjeturo, basado en ciertas teorías sobre el doble, que en estos momentos un hombre nacido el mismo día que yo, quizá de nombre Venzano Torres, transitaba por esa misma calle dirigiendo sus pasos a la Biblioteca Nacional"(Marín, 1997: 112-113). Esto le posibilita al autor un diálogo entre la memoria y la imaginación, con el fin de re-crear un pasado irrecuperable durante el período de gestación de la novela.

Por lo anterior, la creación de una realidad literaria en estos autores, también se suscribe al pensamiento del afuera, en tanto piensa en la imposibilidad que no violenta lo real y permite una nada en movimiento ubicada en el espacio intersticial de 'la desobra', vinculado con el término blanchotiano 'desastre' y 'errancia' .

Esta concepción de la escritura errante aparece desde los prólogos de las obras estudiadas, en los cuales se enuncia su carácter abierto y provisorio en un desplazamiento incesante de la escritura. Por ejemplo, leemos en El arte de la palabra: "pertenece a la especie de obras intrínsecamente inconclusas, esto es, de las que parecen emprenderse para frustrar continuamente todas y cada una de las tentativas que se hagan, desde un principio para concluirlas" (7). Igualmente, leemos 
en Círculo vicioso "es una obra que aún está escribiéndose y ese carácter inacabado que posee, provisorio, tentativo, fragmentario, errático, frente a un interlocutor casi siempre emboscado, le confiere a dicha lectura las mismas oscilaciones que tuvo para el autor la elaboración del texto" (12).

Lo anterior permite a la escritura del errante ubicarse fuera de la dialéctica, vinculada al poder y manifestar la ausencia de todo discurso para afirmarse como la palabra neutra e impersonal, que proclama la alteridad y el extravío. Así, la existencia de la locura y el sin sentido no son mirados desde la negatividad; por el contrario, constituyen una destrucción de formas y crean la "desobra" de la obra, donde está "la nada, fuerza liberadora que opera con violencia negadora sobre toda realidad" (Ruiz de Samaniego, 1999:167). De modo tal, el lenguaje se libera y, con él, elimina la escritura del dominio concebido de la razón para encaminar una escritura del afuera que muestra cómo funciona el sistema, pero sin someterse a él.

En este sentido, El arte de la palabra y la trilogía $H d a f$ son elaboradas, a partir de la experiencia de la dictadura militar en Chile, iniciada con el golpe militar de 1973. Estos textos trabajan una escritura punzante que rechaza el sistema oficial y las figuras de autoridad del país. No obstante, ambas obras convergen en la experiencia del "exilio interior" de sus autores en el uso de un lenguaje anulador de identidades referidas a una realidad y constructor de un mundo pensado como dispersión de cualquier pretensión de verdad y sentido. Así, los autores detectan los fenómenos sin proponer nada. En el caso de Lihn, la novela construye un país imaginario llamado Miranda "un lugar a la vez inexistente y real que explique todos los otros [...] incomprensible coincidencia entre lo verdadero y falso que altera la relación normal entre lo uno y lo otro" (94-95), en el cual el lenguaje es utilizado de manera disparatada, grotesca, paródica y sarcástica como reflejo de una realidad disfuncional de la cual Lihn ha señalado: "aquí no me interesa el testimonio documental sino la experimentación en el laboratorio de la retórica, de los modos de decir y de escribir. No narro una historia de la realidad, sino trato de extraer una realidad del lenguaje"(49). Es más, Lihn realiza un análisis crítico de su obra en una autorreseńa sobre $E l$ arte de la palabra, "El arte de la palabra, Enrique Lihn", aparecida en Point of Contact / Punto de Contacto (1982), y señala: "El lenguaje, pues no como correa transmisora de la realidad [...] sino como máscara de carne y hueso escriturales, como extravío o desvío, respecto de los narradores-personajes "vivos"” (82).

Específicamente, la figura principal de la obra es Gerardo de Pompier -y acá se incluyen los demás escritores invitados-, representante principal de un congreso, realizado en Miranda, destacando por su desdoblamiento, carácter camaleónico, y, sobre todo, por su oratoria delirante y exacerbada con la cual pretende imitar la cultura francesa de mala forma, creando un discurso pomposo y ridículo que él llama "iliteratura" (superabundancia narrativa o hiperlenguaje). Así leemos "Don Gerardo entretejía sus ademanes lingüísticos a nuestras propias crónicas, además de lo que 
funcionaba como un monólogo en que distintas y distantes personas podían confluir y en el que podían disolver su diálogo de sordos. La palabra solitaria de Pompier era el fiel reflejo de las conversaciones, sin salida, de esa época”. (340-341). Aquí, Lihn realiza a una crítica a la palabra exacerbada de los personajes, a la "cháchara", que con decir tanto no dice nada. Este procedimiento expresa el modo viciado del lenguaje que lo ha llevado a su involución, ya que "podía esperarse cualquier acción verbal siempre que cumpliera con los requisitos de la vanidad literaturesca, de un retoricismo obsoleto, de la falta de coherencia" (340). De modo tal, el discurso de los personajes manifiesta la retórica oficial "paródicamente, al vacío de sus propios enunciados acentuando en ella -valorizando- los puntos en que afloraba el inconsciente y la falta de conciencia" (340). Así, Pompier aparece como la contrafigura de Rimbaud, quien en su lenguaje desarticulado trata de desprenderse del orden discursivo y hablar desde el silencio. Por el contrario, Pompier se alimenta a sí mismo desde la "cháchara" "que podía empezar a dibujar en el reverso [...] ese discurso que a fuerza de intentar la reconciliación entre la coherencia racional y la mecánica de los discursos autoritarios debía, en el trance de ese salto en el vacío, henchirse, llenarse de aire y vanidad literaturesca mientras se desgranaba, proliferante, hundiéndose a chorros en la nada a través de la hendidura insalvable"(345).

Asimismo, la obra lihneana también crítica las sociedades autoritarias e ilustra un lenguaje sin sentido que ridiculiza el discurso empleado por aquellas, en tanto es una herramienta vinculada con el poder que vigila y destruye, según Foucault. Leemos en El arte de la palabra:

todo hace esperar de este congreso un resultado irrisorio: la confirmación pues de que el Protector nos ha hecho alojar en este hotel para dispersarnos en la inmensidad, hacernos vigilar [...] por el interés o la voluntad iliteraria de engalanar al poder con el prestigio problemático que le acarrearía la presencia de un grupo de escritores-forzoso es reconocerlo-olvidados (1980: 62).

No obstante, observamos una tercera voz que corresponde al narrador y autor de la novela, que va indicando el sinsentido de las acciones realizadas por el Protector y sus seguidores, incluso sus enemigos (por ejemplo, Gerardo de Pompier), dejando huellas entre los dos discursos expuestos. De modo tal, en palabras de Foucault "lo ficticio no se encuentra jamás en las cosas ni en los hombres, sino en la imposible verosimilitud de aquello que está entre ambos: encuentros, proximidad de lo más lejano, ocultación absoluta del lugar donde nos encontramos. Así pues la ficción consiste no en hacer ver lo invisible sino en hacer ver hasta qué punto es invisible la invisibilidad de lo visible" (1997: 13). En efecto, esta voz se ubica en el entre de los dos grandes discursos expuestos y nos indica "la cháchara" como un modo de expresión en un mundo de opresión, que muestra el poder de las 
palabras institucionalizadas y vigiladas, donde "suspendida la libertad de palabra, el hablante individual, que siempre es a la par colectivo, debe elegir entre el silencio o la cháchara $[. .$.$] muestra los efectos de la represión sobre una palabra vacía"$ (347). De modo tal, los lectores accedemos a la posibilidad de experimentar una nueva versión de la realidad aludida, a través de la escritura del desastre, El arte de la palabra, en la cual se fusionan la lectura del discurso de la "cháchara", el discurso del "Protector" y el narrador/autor, para configurar un afuera abierto que expresa el reverso de lo dicho y lo impensable.

En este sentido, el análisis realizado por Rodrigo Cánovas sobre El arte de la palabra, nos permite observar que la obra de Lihn tiene dos registros: uno consciente y otros inconsciente, vinculados a una lógica específica, donde "yo habla y uno latente, donde el otro (ello) habla por mí" (10). Cánovas plantea el texto de Lihn configurado como un sueńo para verbalizar un discurso que está prohibido a través de un relato acorde a las reglas vigentes del cual "podemos deducir un relato latente que denuncia esas normas infrahumanas"(1986: 28). El crítico ejemplifica su interpretación con la tarea del prologuista, quien relata una narración ficticia sobre el viaje del espeleólogo Albornoz a las profundidades de las cuevas de Ollazo, quien representaría a un Lihn asfixiado por la represión impuesta por el régimen militar. Por ende "probablemente no serán saurios los que encuentre Albornoz, ni muchos menos saurios mutantes y progresivos, sino hombres regresivos, obligados por ciertas circunstancias a esconderse en las intimidades geológicas de Miranda, ese terrón paleozoico"(12). Lo anterior se relaciona con la idea de Blanchot desarrollada por De Samaniego (1999), quien señala: "el habla oscura del sueño es también el habla de lo poético, y el hablar oracular de Delfos. Un habla que no expone ni oculta, que no dice ni calla, sino que indica"(186). Por su parte, Hozven señala respecto a la obra de Lihn: "el trabajo de la escritura abre la escena de la letra a las fuerzas implícitas de la lengua, generando un retorno de lo reprimido implícito en todo discurso. Esta es la revolución psico-socio-lingüística que opera en el discurso todo auténtico trabajo de escritura" (1982:104). De manera tal, Lihn genera un nuevo significado del significante en el signo. En relación con esto, leemos la carta de Roberto Albornoz a Pompier:

posiblemente el Saurio Nuevo - digo yo, el que evidentemente está naciendo en estas tierras, bajo la forma de especies inéditas, de transición- no disponga nunca del instrumento del lenguaje lingüístico [...] en cambio da muestras de una imaginación simbólica que, habiendo recibido, últimamente, por mi intermedio, una orientación científica definida, evoluciona a ojos vistas (1980: 86).

En el caso de la Hdaf, enfocándonos en el diario de vida del autor y en su alter ego Venzano Torres, la obra se basa tanto en la experiencia cotidiana de Marín 
como en el proceso de gestación de la novela, a través de una escritura, que no se deja capturar. Esto le provoca desconcierto, soledad y angustia al recomenzar la tarea. Leemos: "no deja de provocarme cierto miedo cada vez que retomo la novela a fin de proseguir en la tarea de su escritura. Siento frente a mí una obscuridad que, aparte de la zozobra de tener que atravesarla, desconozco donde me llevará” (1997: 39). Junto con esto, presuponemos que la obra de Marín está marcada por la "zozobra" del exilio, vinculado a la soledad de lo interminable e incesante de la escritura del desastre de Blanchot en la cual el sujeto se encuentra ausente en el momento de escribir, ya que:

Lo que se escribe entrega a quien debe escribir a una afirmación sobre la que no tiene autoridad, que es inconsistente, que no afirma nada, que no es el reposo, la dignidad del silencio, porque es lo que aún habla cuando todo ha sido dicho, que no precede a la palabra, porque más bien le impide ser palabra que comienza, porque le retira el derecho y el poder de interrumpirse [...] Además, es retirar el lenguaje del curso del mundo, despojarlo de lo que hace de él un poder por el cual, si hablo, es el mundo que se habla, es el día que se edifica (1992:21).

Por esto, la escritura mariniana se recurva sobre sí misma en el espacio literario que lo atrapa en un tiempo ahistórico. El autor siente una pérdida de control dentro de un lenguaje infinito. En términos de Foucault "el lenguaje no cesa de repetirse" (1994: 86). Así lo vemos en los tres tomos de la trilogía "la escritura tiene repliegues ocultos" (1994: 329), "las palabras nunca traducen donde se quiere llegar, no revelan sino, que más bien ocultan el camino" (1997: 258) y "a medida que avanzo en la obra, casi siempre a tropezones, siento que me voy perdiendo en una espesura cargada de repliegues, de consideraciones, de estupores, de donde no saldré nunca. Escribir desde un pasado reconstruido es hacerse prisionero de uno mismo, de las palabras que no progresan, al menos en el sentido de las manecillas del reloj" (Marín, 2005: 130). En palabras de Blanchot, esta es la experiencia del arte "como imagen, como palabra y como ritmo indica la proximidad amenazante de un afuera vago y vacío, existencia neutra, nula, sin límite, sórdida ausencia, asfixiante condensación donde, sin cesar, el ser se perpetúa en forma de nada" (1992: 217).

Por consiguiente, constatamos que el autor/narrador/personaje Germán Marín percibe el misterio del pasado tanto de su vida como de su escritura; pues a pesar de que ambos son reescritos por él, a través de una escritura provisional, corregida, pulsional y fragmentada, él no logra escapar de la fascinación de hablar sobre el eje de sí mismo y de su escritura. Ese es su ADN, en tanto: "yo era [...] el punto en movimiento de una línea invisible dibujada por nadie, arrojada hacia el futuro" (Marín, 1997: 18). 
Además, es interesante observar que las obras estudiadas convergen en la idea de escribir para un pueblo que falta, un pueblo ausente, de Gilles Deleuze. Recordemos que ambos escritores fueron subyugados en una dictadura militar. Lihn y Marín desean construir una realidad, a través del lenguaje, donde se escribe para un pueblo que falta, el pueblo de los exiliados, de los desarraigados -dentro y fuera- del país. En cierta medida, la literatura funciona como una iniciativa de salud en inventar un pueblo que falta (Deleuze 1994: 4). En efecto, a través de la voz de Pompier, Enrique Lihn habla desde la cháchara y genera el silencio de la escritura del desastre. Es decir, habla desde la censura y habla para vivir "el silencio que yo practico es el silencio del ostracismo activo, de la abstención, del voto en blanco (y ese blanco es un signo, una escritura)" (1980: 156). En tanto, Marín exiliado en Espańa, vive una situación fronteriza en su lenguaje, ante el espańol entre dos orillas del idioma: catalán y espańol. La experiencia del exilio le provoca un tironeo entre la memoria y la imaginación, lo cual le permite manejar el lenguaje con un uso menor e irreverente y sobrevivir en la soledad, ya que "el deseo de asumir el fracaso me aterra, pues si dejara de escribir, en un acto de voluntad, quedaría más desguarnecido aún, abandonado" (1994: 278).

Por todas las razones anteriores, las escrituras lihneana y mariniana se establecen en la fragmentariedad y neutralidad de pensar sin poder ni verdad incondicionada a una presencia, es el pensamiento "sin pensamiento" de Blanchot. Esto crea la posibilidad de que las obras de ambos autores se comuniquen y permitan la especulación y diversas interpretaciones, donde la lectura es una re-creación del procesos creativo de la escritura, que rompe con lo unitario y diversifica las lecturas. En ese sentido, Lihn describe su obra, en la autorreseña del año 1982, antes citada, señalando que:

es un ejemplar sui generis de la literatura de lo grotesco, en Hispanoamérica. No propone ni documenta nada (Ni Cuba ni Chile). Tampoco es sólo una parodia del Modernismo como origen de nuestra identidad literaria y cultural puesto que lo actualiza y lo asume "piadosamente" [...] constituye una pieza brillante de humor negro y se constituye (por lo tanto) en un estudio de teratología referido a las deformaciones de los aspectos retóricos y poéticos de la palabra [...] es asimismo un metatexto-literatura sobre la literatura-que elude al realismo o la documentación; pero que difiere, es claro, de las formas europeas [...] metaliteratura que escapa a la transitividad de por sí y aspira a acceder en si misma, a la pureza una lógica, se convierte en el A. de la P. en un medio de ocultamiento revelador, en una forma de acción contraliteraria, en un cierto tipo de discurso camaleónico pero en último termino realista: una herramienta de palo (83-84).

En el caso de la trilogía de Marín, la escritura del desastre aparece con la extrañeza del lenguaje. Es decir, la desterritorialización del lenguaje español, el 
cual el autor maneja irreverentemente cuando modifica la sintaxis para utilizar oraciones largas casi sin puntuación en una continuidad exacerbada. El crítico Camilo Marks describe la escritura de Marín de la siguiente manera:

una sintaxis endiablada, descoyuntado, febril, culto o popular, por momentos de una precisión alucinante, a veces casi inconexo, somete a la lengua a severas pruebas, experimenta de manera constante y es, en la práctica, un milagro que tal serpenteo redoblado con las palabras jamás pierda de vista el hilo de la trama, que resiste, intacto, todas las acometidas retóricas del escritor (2010: 224).

Lo cual se relaciona con la escritura descrita por Deleuze: como "el conjunto de giros necesarios, creados cada vez, para revelar la vida de las cosas" (1994: 15). Este mecanismo surge como paradoja de una presencia-ausencia de un devenir entre la memoria y la imaginación, una literatura 'escribivivida', término empleado por Marín para referirse a la fusión de las palabras escritura y vida en su obra, cuyo origen diferido se plasma en la borradura de la propia escritura que funciona como una huella fundamental en su proceso de (re)creación.

En definitiva, ambas obras visibilizan y exceden el poder y su ley al hablar a partir de la cháchara y la zozobra por medio de las cuales se evidencia las consecuencias de aquel en los personajes. Por medio de este procedimiento, los autores reconocen un desgaste del lenguaje subordinado a la voluntad del poder y muestran un lenguaje insubordinado que, según Foucault, delata la articulación de la ley y la inducen al afuera para ver su visibilidad (1997:22). Concretamente, los personajes de las obras estudiadas provocan muchas veces la ley para hacerla visible, como es el caso de Gerardo de Pompier y su protesta frente al Protector, que son sancionadas con su expulsión de Miranda y la desaparición de algunos de los escritores. Por ejemplo, Pompier en una entrevista a Carré, reconoce "no hay ninguno que escape a la ley de la Ley. Yo que postulo para mí y quienquiera que sea, internos, y que practico hasta donde ello es posible la evasión de estos Ordenes arbitrariis en nombre de una excepción que confirma la regla, puedo decírselo" (182).

En el caso de la obra de Marín, la lectura de los periódicos y de la correspondencia de sus amigos en Chile, entre ellos, Enrique Lihn, el texto muestra el funcionamiento de la ley dentro de Chile y sus consecuencias en el exilio. De esta manera, Marín se siente un apátrida "no he vivido en países, sólo habitaciones" (Marín, 1997: 56). Lo previo se relaciona con su condición de exiliado, ya que:

A pesar de llevar diez años de exilio, nunca había salido del país remoto. Continuaba prisionero en él, pegado como una mosca a la mugre [...]. Es una sensación claustrofóbica, llena de signos enigmáticos, pero a la vez familiares, donde veo a la distancia erguirse la Cordillera de los Andes como una amenaza que me abruma, 
hermosa y nevada, la cual a medida que observo encadenado a esos sueños se vuelve cada vez más nítida en la visión, más alta, más carcelaria, parecida a esas imágenes de Magritte que, a pesar de la transparencia expuesta, no revelan el sino de su misterio (Marín, 1997: 144-145).

Particularmente, el tema del exilio aparece en ambas obras relacionado con la reflexión de Blanchot, quien plantea que la escritura es el lugar del exilio (Ruiz Samaniego, 1999: 212), donde los escritores exiliados sienten una insatisfacción por estar en el extranjero, fuera de sí mismos y de su lugar de origen, su presencia está extraviada en una región donde nada permanece (1992: 12). Así, el exilio aparece como un no lugar al que son expulsados los personajes. Por una parte, en El arte de la palabra, el exilio es concretado al final de la obra cuando Gerardo de Pompier y los escritores son expulsados de Miranda por enfrentarse al discurso del poder. Por otra parte, la escritura mariniana describe la estadía en el exilio en el que habita el personaje/narrador Germán Marín, angustiado y solitario, en los tres tomos de la trilogía.

Finalmente, las obras indican un panorama crítico y negativo, solo posible de ser retratado a través de una construcción lingüística a la deriva, que escapa al modo del orden discursivo a través de "la palabra poética" del pensamiento del afuera ligado al "habla del lenguaje". Esto expresa la profundidad de la imaginación en un presente provisorio, en constante movimiento, que imposibilita la rigidez de establecer categorías y, en cambio, permite deambular entre la verdad y la ficción. En este sentido, Foucault propone "la ficción del pensamiento", desde la experiencia del afuera, como una dimensión exterior del lenguaje producida cuando se acepta el "habla" de este, en tanto "nada tiene derecho a limitarlo-ni aquel al que se dirige, ni la verdad de lo que dice, ni los valores o los sistemas representativos que utiliza; en una palabra, ya no es discurso ni comunicación de un sentido, sino exposición del lenguaje en su ser bruto" (1997: 5). Así, las obras de Lihn y Marín están establecidas en la neutralidad de la escritura, donde la ley es excedida y surge lo "no pensable", sin pertenencia, en ausencia del mundo, donde la palabra misma es el "habla del habla" alejada del dominio de la racionalidad. Podríamos señalar, que esta es la zona muda de la que habla Lihn en su libro Diario de muerte (1989): "nada tiene que ver la desesperación con la desesperación "las palabras que usamos para designar esas cosas están viciadas. No hay nombres en la zona muda” (13).

En efecto, Lihn y Marín coinciden con los postulados de Foucault sobre el espacio intersticial del afuera, con la neutralidad de Blanchot y con el devenir de Deleuze, en tanto se refieren a un "entre" o a un "no-lugar", donde el lenguaje puede liberarse del sujeto, de sus connotaciones y representaciones, volver hacia sí mismo, en un murmullo interrumpido de retorno a la propia literatura, donde el lenguaje del ser es el silencio: la involución de la escritura. 


\section{Agradecimientos}

La autora agradece el patrocinio, en su investigación posdoctoral 20142016, al Council on Latin American and Iberian Studies en el Whitney and Betty MacMillan Center for International and Areas Studies, en la Universidad de Yale; asimismo, agradece a la Comisión Nacional de Ciencia y Tecnología (Conicyt) y a la Universidad de Concepción.

\section{REFERENCIAS}

Blanchot, Maurice. La escritura del desastre. Caracas: Monte Ávila Editores, 1990.

Blanchot, Maurice. El espacio literario. Buenos Aires: Paidós, 1992.

Blanchot, Maurice. Michel Foucault tal y como yo lo imagino. Valencia: Pre-textos, 1993.

Cánovas, Rodrigo. Lihn, Zurita, Ictus, Radrigán: Literatura chilena y experiencia autoritaria. Santiago, Chile: FLACSO, 1986.

Coloma, Marco Antonio. "Soy un resentido, de todo". (Entrevista 2003, eneromarzo). [Versión electrónica]. Revista Libros y lectores, No 1, 53-61. Disponible en: http://www.letras.s5.com/marin300403.htm. [Consultado el 05 de mayo de 2010].

Deleuze, Gilles. La Literatura y la Vida. Córdoba: Alción, 1994.

Edwards Renard, Javier. "El segundo escribiviente”, El Mercurio (suplemento) 3 (2 de agosto de 1997).

Espinosa, Patricia. "No hay primera sin segunda”, La Época (suplemento) 34 (22 de junio de 1997).

Fernández Gonzalo, Jorge. "Maurice Blanchot y el pensamiento de la no-relación”, Revista Neutral. Edición \#3/ 02.12. Disponible en: http://revistaneutral. wordpress.com/2012/02/02/maurice-blanchot-y-el-pensamiento-de-lano-relacion-por-jorge-fernandez-gonzalo/.

Filebo (Luis Sánchez Latorre). “Abú Lihn o a tientas y a locas”, Las Últimas Noticias, Santiago de Chile (13 de diciembre de 1980), p. 7. 
Filebo (Luis Sánchez Latorre). "Los tiempos del Círculo Vicioso", Las Últimas Noticias, Santiago de Chile (8 de enero de 1995), p. 14.

Foucault, Michel. De lenguaje y de literatura. Barcelona: Paidós Ibérica, 1994.

Foucault, Michel. El pensamiento del afuera. Valencia: Pre-Textos, 1997.

Foxley, Ana María. "Enrique Lihn. En la jaula de los loros", Hoy 177 (10 al 16 diciembre de 1980), pp. 48-49.

Fuentes Leal, Mariela. "El vuelo desterritorializante de Las cien águilas de Germán Marín". Tesis de Magíster no publicada. Concepción, Chile: Universidad de Concepción, 2006.

Guerrero, Eduardo. "Un lúcido ejercicio novelesco”, La Segunda, 42 (13 de marzo de 1995).

Hozven, Leonidas Roberto. "El arte de la palabra”, Estudios Filológicos, 17 (1982), pp. 99-109.

Lastra, Pedro. Conversaciones con Enrique Lihn. Santiago, Chile: Atelier, 1990.

Lihn, Enrique. La orquesta de cristal. Buenos Aires: Editorial Sudamericana, 1976.

Lihn, Enrique. Lihn \& Pompier. Santiago, Chile: Edición del Departamento de Estudios Humanísticos, Facultad de Ciencias Físicas y Matemáticas, Universidad de Chile, 1978. [50 p. Ilust.].

Lihn, Enrique. El arte de la palabra. Barcelona: Editorial Pomaire, 1980.

Lihn, Enrique. "El arte de la palabra, Enrique Lihn", Point of Contact / Punto de Contacto. New York, Vol. III, No 1/2, (Summer 1982): 81-88. También, en El circo en llamas (1997), pp. 589-597.

Lihn, Enrique. Diario de muerte. Textos reunidos y transcritos por Pedro Lastra y Adriana Valdés. Santiago, Chile: Editorial Universitaria, 1989.

Lihn, Enrique. El circo en llamas. Ed. Germán Marín. Santiago, Chile: LOM, 1997. 
Marín, Germán. "Enrique Lihn: Literatura no invoco tu nombre en vano”, Camp de L'Arpa. Barcelona (octubre de 1978), pp. 55-56, 67-69.

Marín, Germán. Círculo vicioso, primer volumen de la trilogía Historia de una absolución familiar. Santiago, Chile: Planeta, 1994.

Marín, Germán. Las cien águilas, segundo volumen de la trilogía Historia de una absolución familiar. Santiago, Chile: Planeta, 1997.

Marín, Germán. La ola muerta, Tercer volumen de la trilogía Historia de una absolución familiar. Santiago, Chile: Random House Mondadori S.A., 2005.

Marín, Germán. Basuras de Shanghai. Santiago, Chile: Random House Mondadori, 2007.

Marín, Germán. Discurso en ceremonia del Premio Atenea, 14 de noviembre de 2008, Casa del Arte, Universidad de Concepción.

Marks, Camilo. "Fuera del círculo en llamas", El Mercurio (suplemento) 3 (21 de octubre de 2005).

Marks, Camilo. “En busca del tiempo vivido”, La Época, 3 (29 de enero de 1996).

Marks, Camilo."Persistencia de la memoria”, ElMercurio, E 18 (05 de abril de 2009).

Marks, Camilo. Canon, Cenizas y diamantes de la narrativa chilena. Santiago, Chile: Debate, 2010.

Marras, Sergio ."Enrique Lihn en el espacio de lo imaginario", Bravo 49, Santiago de Chile, (1981): 4-7 y 9.

Matus, Álvaro. "Uno le teme más a las palabras que a los hechos”. (Entrevista 30 de septiembre de 2005), El Mercurio (suplemento), 6-7.

Matus, Álvaro. “Soy reaccionario de alma y progresista de vocación”. (Entrevista 05 de agosto de 2007), El Mercurio (suplemento), E 16-E 17.

Mejía, Jorge Mario. Blanchot y el pensamiento literario. Medellín: Editorial Universidad de Antioquia, 1999. 
Moscoso, Patricia. "Enrique Lihn, un escritor a la intemperie", Cosas 81, Santiago de Chile, (8 de noviembre de 1979): 32-33.

Osorio, Daniel. Germán Marín. "Escribo porque no morí a tiempo". (Entrevista 15 de julio de 1997), La Tercera, 44.

Ossa, Carlos. "Un círculo sumamente vicioso", Punto Final 335 / 22 (05 de febrero de 1995).

Oyarce Orrego, Alejandra. Escritura fractal como expresión de una cultura fractal: La cultura chilena. Tesis de Pregrado no publicada. Concepción, Chile: Universidad de Concepción, 2000.

Pinto, Rodrigo. "La ola muerta", El Mercurio, 18 de marzo de 2006, en el suplemento El Sábado, p. 7.

Promis, José. "Relato a cuatro manos", Hoy 1043, 53. (27 de julio de 1997).

Rivera, Angélica. "Lo imaginario también es lo real". Las Últimas Noticias, Santiago de Chile, 13 de junio de 1997, p. 32.

Ruiz de Samaniego, Alberto Luis. Maurice Blanchot: Una estética de lo neutro. Vigo: Universidad de Vigo, Servicio de Publicaciones, 1999.

Samarriva, Marcelo. "Dejar de escribir es fácil, basta meterse la mano al bolsillo". (Entrevista 10 de agosto de 2003). El Mercurio, E4-E5. 